\title{
LOCOS Y LOCURA EN BERCEO
}

\author{
A mi maestro Alonso Zamora Vicen- \\ te, en testimonio de una vieja (y ac- \\ tual) gratitud.
}

No creemos desatinado iniciar el censo del vocabulario de la vesania en la obra de Gonzalo de Berceo $^{1}$ con las palabras que la máxima creadora de novelas policiales - y, por ello y en ello, finísima catadora de matices psicológicos - pone en boca de uno de sus personajes, alienista de profesión:

...La señora Eversleigh había conseguido que el gran hombre hablara de su profesión:

- Mi querida señora - le estaba diciendo-, ¿qué es la locura? Le aseguro que cuanto más estudiamos el tema, más difícil se nos hace el precisar. Todos practicamos el autoengaño, y cuando lo llevamos hasta el punto de creernos el zar de Rusia, se nos encierra o aísla. Pero hay un largo trecho antes de llegar a este extremo. ¿En qué punto preciso podríamos instalar un poste que dijera: Aquí termina la cordura y empieza la locura? Ya saben ustedes que no puede hacerse. $Y$ les diré una cosa: si el individuo que sufre ese embaucamiento propio no dijera nada, es probable que nunca pudiéramos distinguirle de otro normal. El extraordinario sentido común de los locos es un tema interesante.

${ }^{1}$ Todas las citas de Berceo proceden de la editio princeps por THOMÁs ANTONIO SÁNchez, Colección de poesías castellanas anteriores al siglo xv, t. 2, Antonio de Sancha, Madrid, 1780. Se utilizan también las abreviaturas de su "Índice alfabético de las voces antiquadas": SDom (Vida de Santo Domingo de Silos); SMill (Vida de San Millán); Sacrif (Sacrificio de la Misa); SLor (Martirio de San Lorenzo); Loor (Loores de Nuestra Señora); Sign (Signos del Juicio); Milag (Milagros de Nuestra Señora); Duel (Duelo de la Virgen María) y SOr (Vida de Santa Oria). 
Más que muchos sesudos párrafos psiquiátricos, el propos de table de Sir Alington West define la imprecisión que nuestra ciencia y nuestra experiencia de hoy reconoce en las fronteras de la razón y el desvarío ${ }^{2}$. Empero, en el cristalizado universo de nuestro primer poeta, donde el bien y el mal se encarnan en dos polos resueltamente opuestos, no puede haber lugar para lo que aparecería allí como un imposible contubernio. Tan antitéticas como Dios y el diablo, la razón y la locura absolutas se muestran también diametralmente distanciadas, la una como don del Hacedor, la otra como sugerencia del enemigo.

La razón -en el sentido absoluto que el Diccionario de la Real Academia le asigna casi únicamente en la locución que expresa el hecho de perderla- es en Berceo ya el discurso mismo (SDom, $399 c ;$ Milag, 60d), ya, sobre todo, la materia misma que otros han tratado y él va exponiéndonos (SMill, 320a; Sign, 48b; Milag, 618a, $704 a$ y $768 c$; SOr, $34 b$ y $202 b$; uno y otro sentido en Milag, $806 a$ ); en SDom, 62a, se dice que un proverbio "fabla por razón", esto es, dice verdad, y en Milag, 60c "pocos vierbos" proporcionan "razón buena complida", contienen muchas verdades. "Razonar" vale por suministrar aquel material narrativo $(\mathrm{SOr}, 5 \mathrm{c})$, y también por el anticuado 'abogar' (Loor, 220d); lo que hoy entendemos generalmente por razón el poeta lo denomina una vez "razonidad": la bondad divina es tan poderosa, "que a la bestia muda da razonidad"' (SDom, 14d).

Las voces que designan nuestra actual razón son primordialmente "seso", "cordura" y sus derivados. "Seso", en el valor que se le da hoy generalmente (aunque tachado de anticuado por el diccionario académico), y que se conserva en nuestro actual "sesudo" y sus derivados, vale a veces por 'sentido' a secas, tanto el de un texto (Santo Domingo ponía en el de todo lo que leía y practicaba toda su agudeza, 39ab; y en el padre nuestro "las

${ }^{2}$ Similar a la prudencia del personaje de Testigo de cargo (trad. C. Peraire del Molino, Edit. Molino, Barcelona, 1983, "La señal roja", p. 47) es la insistencia con la que Bruno Cassinell (Historia de la locura, trad. J. Noguín, Iberia-Joaquín Gil, Barcelona, 1942), repite fórmulas como ésta: "El médico será, pues, el llamado a demostrar, si lo cree posible, que existe una distinción precisa entre el estado físico y mental de un loco y el de un hombre razonable" (p. 14), y sobre los diferentes puntos de vista del filósofo, el juez y el magistrado (pp. 15 ss). Mi ilustrado amigo el Dr. Michel Marty, colega de Sir Alington West, me propone el terminante deslinde de LACAN, cuyo examen sobrepasa el propósito y el alcance de estas notas: "terme maintenant banni de la psychologie, à cause de sa résonance péjorative" y "supprimé même dans le langage administratif', La Psychologie moderne de A à $Z$, Centre d'Étude et de Promotion, Paris, 1967, s.v. Folie. 
palabras son pocas, mas de seso cargadas', Sacrif, 254c), como las "aptitudes que tiene el alma, de percibir, por medio de determinados órganos corporales, los objetos externos" (Diccionario de la Academia): Garci Muñoz, antes de ser milagrosamente guarido por Santo Domingo, "de todos los sesos ninguno non sentía" (400b); y la antífona que canta los cinco gozos de María los equipara y contrapone con los "cinco sesos del cuerpo que nos facen peccar, / el ver, el oír, el oler, el gostar, / el prender de las manos que dicimos tactar" (Milag, 121b-d). Pero "seso" designa primordialmente el buen sentido, el equilibrio mental y el uso correcto de esas facultades: Santo Domingo se atreve a reprender al rey Don Fernando el Magno sin decirle "cosa desaguisada" aunque se reconozca humildemente como el "de seso más menguado" de su convento (136cd); tanto Oria como Emiliano se alaban mediante el topos del "puer senex" por el uso de la voz "seso": la una "Ninna era de días, de seso acabada", y el otro era "anciano de seso, mancebo de edat' (SDom, 317c; SMill, 39b), mientras que nadie como Judas "fizo tan mal seso" (Sacrif, 209c). Al pedir a Cristo que les enseñase a orar, los apóstoles "dicían seso" (id., $250 b$ ), mientras que la serpiente que engañó a nuestros primeros padres "los sacó de seso con sermones arteros" (Loor, 4b). San Ildefonso, al buscar cómo servir a la Gloriosa, "facíe en ello seso e buena providencia" (Milag, 60d), mientras Nuestra Señora, durante su Duelo, sabía que "sin seso andaba" (136d), se tenía "por sin seso del planto que facía"' (137d), y si después de haber caído " amodorrida", recuerda, nos dice: "cobré el seso"' (17b y 18a): y manifiesta además que quien le hablase por entonces de cosas de alegría "non serie de buen seso" (47d); y María la de Castro Cisneros pierde, para recobrarlo gracias a Santo Domingo, "su seso" (305c y 310b). "El seso de los omes flaco es e menguado, / non vale contra Dios un tiesto foradado" (Duel, 198ab), y los que intentaron levantar la torre de Babel son dichos con verdad "mancebos de mal seso que con Dios se tomaron" ( $i d ., 200 c)$ : pero, falible y todo, el seso del hombre puede mejorarse (sobre el seso "natural" cabe uno "complido", Milag, 859d): San Vicente y San Lorenzo, al ser educados por su pariente San Valerio, "en prender el su seso fueron bien acordados" (SLor, 4a), y para entonar la alabanza de Santa Oria el poeta confiesa que "menester nos será todo el seso que avemos"' $(19 d)^{3}$.

${ }^{3}$ Para la expresión "que con seso quebraba" (Milag, 724a) y para el valor general de "seso", me permito remitir a "Quebrar", pp. 47-51 de mis Textos y contextos, Gredos, Madrid, 1974. 
Compañera y calaña del seso es la voz "sen" que el Himno I, 6a, solicita del Espíritu Santo (cf. Milag, 225b y 707d), con su derivado "senado" (lo es el abad de San Millán al acoger nuevamente a Santo Domingo, 114a).

"Cordura" - y los adjetivos emparentados cuerdo, acordado, etc. - sigue en frecuencia a seso y su familia, en una proporción semejante a aquélla con que cordura reemplaza a seso en el 'Duelo de Nuestra Señora ("Qua io mal estordida en cordura non seo", 123d). Los veladores del 'Duelo, al resucitar Cristo, "perdieron el sentido y toda la cordura" (194b); privado de "memoria, fabla \& visión", nuestro Garci Muñoz "non avie nul acuerdo, nin entendie razón" (SDom, 399bc). "Acordado" es uno de los calificativos más frecuentes en el poeta (incluso en su sentido musical): lo son San Pedro (Loor, 139a) y San Jerónimo, presunto autor - y en realidad lector y traductor- del original de los Signos (4a); San Millán y San Felices, al dejar los poblados por el yermo, "fueron, sin dubda, omes bien acordados" (SDom, 60a), como lo fueron los frades de San Millán al procurar que los casados de Prades, rendidos de dolor, comiesen algo (SMill, 351a), y como fue el protagonista del Milagro tercero en saludar continuamente a Nuestra Señora (102b); "mal acordado" (o mal aconsejado, de no obrar por propia determinación) es el rey Don Fernando al requerir los tesoros del monasterio de San Millán $(S D o m, 140 a b)$. Y San Sixto, papa segundo de este nombre, se plugo con la compañía de San Valerio y sus discípulos porque "fablaban cuerdamientre" (sus "dichos certeros" los calificaban además para la disputación, SLor, 9cd).

En el campo opuesto, "locura" y, sobre todo, "follía", acompañadas de unas pocas voces más, dominan el campo. Si San Ildefonso demostró tener seso, Siagrio su sucesor, obrando contrariamente, "fue luego enfogado por la su grand locura" ( $M i$ lag, 72d); el monje de Colonia que protagoniza el milagro séptimo "era de poco seso, facie mucha locura" (161a); en las mismas gentes del judaísmo "quebraron todas las sus locuras" (id., 417d), así como (según la aljama) el de Constantinopla que hizo "tan loca fiadura", "perdió su aver por su mala locura" (id., 680c y b). Cuando Peydro, cautivo en la de Alarcos, duda de poder salir de prisiones, Santo Domingo, "que li traye las nuevas, / Pedro, dixo, en esto por mui loco te pruebas" (713ab). Don Fernando, que mandaba León y Castilla, apostrofa al mismo santo que lo ha reprendido: "sodes de mal sentido, como loco fablades" (143a); María la de Castro Cisneros, antes de que el santo le diera salud, "fablaba de la lengua mucha palabra loca" (293b); y cuando Santo 
Domingo, ya muy enfermo, anuncia la próxima llegada del Obispo y - más oscuramente - la festividad de la Encarnación, "avie entre los Monges por esto grand roydo, / tenían alquantos dellos que era enloquido", a lo que él les responde: "Non ha entre vos todos un[o] bien acordado"' (509ab y 510c). Y en la contienda entre San Sixto y Decio ambas partes se van acusando sucesiva y mutuamente de desvarío: "Dissol Sixto a Decio: dices gran desmesura, / semeias ome cuerdo, e dices grand locura' (SLor, 37ab); "Dissol Decio a Sixto: eres mal razonado" (39a); "Sixto, dissoli Decio, semeias enloquido" (42a); "Dissoli Sixto: Decio, fablas gran vanidat"' (43a): y San Lorenzo hereda el dicterio, esta vez de boca de Valeriano (si bien Sánchez opina que en todos los casos "donde Berceo pone Decio, debe entenderse Valeriano" "): "disso Valeriano: / Laurencio, más semejas enloquido que sano" (93ab). Y si Poncio Pilato se dio muerte ("por sí se mató", Loor, 121c) fue también porque "era enloquido".

Tan frecuente como el de la voz locura y su familia toda es el uso del anticuado "folía" y la corta suya: querer enumerar las incontables mercedes de Cristo "serie follía en sólo lo asmar" (Loor, $53 b$ ); el monje impúdico del milagro segundo es nombrado sacristán porque el abad de su convento "tenielo por cuerdo, e quito de follía" (77d); Huberto, sacristán de San Salvador de Pavía, era también hombre "cuerdo e sin follía" ( $i d ., 287 c$ ); los romeros que ven las almas de sus compañeros ahogados subir al cielo en forma de palomas se dicen que en salvarse "nos cuidamos fer seso, e ficiemos follía"' (id., 603d); las quejas del prestamista de Constantinopla contra Cristo y su Madre son "palabra loca", aunque para él, que no podía creer en su divinidad, Jesucristo "fo ome cuerdo e sin follía"' (id., $688 a$ y $643 c$ ). Y tales truferías, alevosías y cosas desapuestas decían de Cristo y sus compañeros los veladores del Duelo que "pesó al Rey del Cielo de tan grandes follías" (191c). Mucho más raro es el uso de dos voces, usadas traslaticiamente:" sandio" ('necio' o 'simple', que el poeta emplea como trisílabo, acentuando la $i$ ) y "radío" ("errante'): se las pone juntas en boca del mercader constantinopolitano: "Entiendo que me tienes por loco e sandío, / que non traio consejo e ando en radío", (Milag, 646bc: compárese con la defensa que de su capellán hace ante el obispo Santa María: "Judguéstilo por bestia e por cosa radía", id., 230c).

Estos enajenamientos pueden producirse por causas naturales, de modorra a intoxicación, o, a lo menos, semejarse a los pro-

${ }^{4}$ Op. cit., pp. 227-228. 
ducidos por ellas: Guirald, el romero de Santiago, al resucitar "estido un ratiello como qui descordado, / como ome que duerme e despierta irado" (Milag, 210cd); los veladores espantados por la Resurrección "perdieron el sentido e toda la cordura: / todos cayeron muertos... Recordaron bien tarde... no vedien de los ojos todos escalabrados, / feriense unos con otros como embellinados", ('Duel, 194bc, 195ac); el clérigo embriagado "bebió mucho del vino... embebdóse el loco, issió de su cordura, ...recordó mala mientre, andaba estordido, / issió contra la claustra hascas sin nul sentido" (Milag, 463bc, 464bc). Los casados de Prado, padres de una niña resucitada y guarida por San Millán, " andaban dando vozes como embelliñados... andaban enloquidos"' (SMill, 344c y $347 a)$; y en los dicterios de la Virgen que hacen volver sobre sí a su canónigo de Pisa todas estas causas - más, incluso, un adjetivo originariamente salido de la estrellería- se conjugan coordinadamente (Milag, 340):

Don fol, malastrugado, torpe e enloquido, en qué roídos andas, en qué eres caído?

Semeias erbolado que as ierbas bebido, e que eres del blago de Sant Martín tannido.

Lo más usual, sin embargo, es remontar este desorden y desvarío a su causa primera: el triunfo - pasajero- del enemigo del género humano 5 . Diago, el demoniado de Celleruelo (SDom, $627-629)$ :

Avie un fuert demonio, prendielo a menudo, oras lo facie sordo, oras lo facie mudo, faciel a de las veces dar un grito agudo, el mal huésped facielo seer loco sabudo.

Si non porque estaba preso, \& bien legado, farie malos trebeios, iuego desaborado, o a sí o a otri damnarie de buen grado, como non avie seso era mucho ossado.

Vivien en esta coyta con él noches, \& días, si lo dixassen suelto farie grandes follías, querríanlo ver muerto los tíos, \& las tías, ca dicie dichos locos, \& palabras radías.

5 "La Teología cristiana proporciona a la Filosofía la más importante definición de la locura: los locos son como los niños: sicut infantes ... mas ¿cuál es la fuerza capaz de volver niño al hombre? ...La Iglesia, o más exactamente los teólogos, curas y exorcistas, responden: El demonio", Cassinelli, op. cit., p. 22. 
A la de Peña Alba, muda y desmemoriada, "prendíala a menudo la bestia percodida, / andaba en radío como cosa tollida, ....andaba radía como loca" (id., 680ab y 681a; sus miserias y su guarimiento toman las coplas 679 a 699 del poema). Y a un evangelistero que San Millán socorre, entre otras horruras, "facieli el demonio decir grandes locuras" (158ab).

Religión y moral estando tan estrechamente ligadas que saben en realidad a una sola convicción operante todo lo más sobre dominios diferentes, aparece como obligatorio el tránsito de la obra del pecado a la de los pecados mismos que aquél inspira en los humanos: la de Peña Alba 'era una demoniada', pero a la vez "era por sus pecados duramientre lazrada"' (SDom, 679a y b). De aquí a la equiparación de la locura con todo acto vedado por la moral religiosa hay un solo paso - estrictamente canónico- que Berceo no titubea en avanzarnos: así, una vez curado el siervo de Tuencio por la expulsión de cinco demonios que lo atormentaban, San Millán "mandol cómo visquiesse, non amasse follía" (168a). Follía es también dicha la conducta de los de Cantabria (id., 283b; Sánchez $z^{6}$, llama a su destrucción "castigo de sus pecados"), y las amonestaciones del santo a sus moradores le valen las "palabras locas de fea parescencia" que le dirige uno de ellos, un caballero de nombre Abundancio, que lo moteja de "senex puer", ' llamándolo "vieio e loco e desmemoriado, / que en seso de mozo ninno eres todo tornado" (285by $284 c d$ ). De caer en este mal no están, ni con mucho, libradas las gentes de Iglesia: San Millán, cuando era racionero de Santa Eulalia, "metía doctrina sana entre la clerecía, / ca tales avie dellos que trayen follía" (96ab); el monje fornicario del milagro segundo se ahoga cuando "se venie él de complir su follía" (81c); el clérigo embriagado, si bien libre "de follía de fablar en fornicio", pide auxilio a la Virgen rogándole "no pares mientes a la mi gran follía", que fue la de beber vino en exceso (id., 475d); y el padre de Santa Oria, García, es apellidado "aquelli que non quiso seguir malla follía"' (85d). Es así como por la aposición de las dos nociones vecinas que la componen se acuña la repetida fórmula "loco pecador": tal es el "beneito" incontinente (Milag, 79a); también lo es, por ser conjuntamente "mal aventurado", "diablado" y "demoniado" (id., $361 a, c, d)$, el jadre del niño judío (362c). El romero de Santiago, "ante que fuesse monge era non bien senado, / facie a las de veces follía e peccado", y así por seguir el consejo del "falso Iacob" pucde calificárselo de "astroso locco e desessado" y de "fol mal

${ }^{6}$ Op. cit., p. 149, nota. 
venturado" (id., 183cd, 192a, 193a y c). A los que salidos de León van a robar la iglesia de Zohinos "guiolos el peccado" (id., 871c), y movidos por el diablo cometieron "esta tan grand locura" (879a): su primer castigo fue que "andaban en radío los que por mal nacieron... los locos malastrugos... andaban como beúdos" (884d, $887 a b$ ), y cuando el obispo leonés reúne a la clerecía para juzgar a uno de los ladrones por ser éste un clérigo, al informar a los del concilio sobre su pecado lo llama locura: "dissolis su follía" $(900 d)$. La contraposición del pecado con el equilibrio de la razón se expresa cumplidamente a propósito de la Resurrección del Señor: "Creyeron la verdat los que seso ovieron,/doblaron su peccado los que la non creyeron" (Loor, 128cd).

No sería Berceo, sin embargo, el poeta que es, si no dejara abierta la posibilidad de una oposición entre las fuerzas del alma y la del mal enemigo: el clérigo protagonista del milagro de la flor $(101,102 a b)$ :

...que era tiest herido, ennos vicios seglares feramient embebido, pero que era locco, avie un buen sentido, amaba la Gloriosa de corazón complido.

Como quiere que era en el mal costumnado, en saludar a ella era bien acordado...

Nos señala también - y es más raro- la posibilidad de su no conciliación aquí abajo: otro Garci Muñoz (no el de Gomiel, bueno y sensato, sino otro, homónimo, de Yecla, y "tal, que avie dercho de seer enforcado" (SDom, 419d), una vez salvado de la horca por el santo de Silos, como "loco malastrugo... tornó a su locura el malaventurado" (423a y $c$ : su locura consistía en hurtar las mieses de sus vecinos, coplas 420-421 y 423-424), por lo que el santo solicita su castigo (que toma la forma de pérdida de la memoria y la mengua en el uso de sus miembros) y rehúsa curarlo de sus majaduras, diciéndole $(429 c-d, 432)$ :

...Lo que te ovi dicho por esto lo dicía, que si nunqua tornasses en essa tal follía, cadrías en logar malo, \& en grand malatía.

Mas vale que enfermo a paraíso vayas, que sano, \& valient en el infierno cayas, conviene que lo sufras, maguer lacerio trayas, ca de tornar qual eras esperanza non ayas.

Esta constante interacción contrastada de las voces que designan la rectitud y la falta literal de juicio se expone largamente en 
los Milagros: la abadesa del vigésimo primero (en la que sin embargo "iacie mucha bondat", 506a), "cadió una vegada, / fizo una locura que es mucho vedada"7. Aquéllas de sus ovejas que eran algo más negras ("locas malfadadas" las denomina el poeta, y reconoce nuevamente con honesta resignación que "cunte a los prelados esto a las vegadas", $510 c d$ ), recurren al obispo, que idénticamente bien entendido, colige "o que avien contienda,o ficieron follía" (512b). Sabemos por el poeta que la abadesa, trasunto de otra lejana y también feliz culpa, "peccó en buen punto" $(505 b)$ y que en tomar "buen consejo la bienaventurada... fue maravilla cómo fue acordada" $(516 c d)$, de suerte que todo el suceso fue para bien, hasta el punto que el fruto mismo de su azar fue bienquisto de todos, "fuera algunos foles que amaban follías", $(586 d)$. También Teófilo, que antes de caer en pecado era bien adornado "de sen e de ciencia" (707d), " asmó fiera locura, ierro grand, desguisado" (720d) vencido por las dos sólitas y solidarias enemigas "venciólo su locura e muebda del peccado" (727b). Pide por ello consejo a un "trufán diablado" (727c), actuando ante él, según podía esperarse, "como embelliñado" (729a); y al tornar en "sus sesos que iacien amortidos" (749c), advierte la exacta causa de su perdición: "matóme mi locura"' (753b), y se vuelve entonces hacia la misma que denegó "como loco sendío" (766a) y que antes de salvarlo le vuelve sus oropias palabras justicieras: "Sobre yelo escribes, contiendes en locura" (778b), "faces peticiones locas e sin color" (779a: recuérdense los "dichos colorados" del libro de San Ildefonso, $51 b$, y la "palabra colorada" de la misma Gloriosa, 89a), tal como a su vez lo hará el obispo de Adana en Cilicia al resumir públicamente el "pleyto"' de su vicario arrepentido: "moviólo su locura" (840a).

El propio poeta, al contraponer su condición de pecador mezquino con el día tremendo del Juicio, se considera tributario de la locura de este mundo falaz (Loor, 176b, 177a, 180ab):

...siempre fixi e dixi vanidat e folía...

Oy mal Evangelios, amé siempre locura...

Quando era en la eglesia las horas me enojaban, los pensamientos vanos de seso me sacaban...

Queda así bien clara, una vez más ${ }^{8}$, la unitiva claridad en la

${ }^{7}$ Sobre la convicción de Berceo, patente en $527 b$ ("aquesta erranza") y 549 ("Toda monia que face tan grand desonestat, / que non guarda su cuerpo nin tiene castidat..."), cf. "Pisó yerba enconada", pp. 11-46 de Textos y contextos.

${ }^{8}$ Para un examen similar de otro aspecto unitario de la obra de Berceo, 
expresión del pensamiento de Berceo: un grupo no muy amplio de voces equivalentes ${ }^{9}$ define la oposición que existe entre la cordura y la ausencia de razón, manifiesta esta última espiritual o somáticamente como consecuencia de una infracción a la moral impuesta por la creencia, de acuerdo con una tradición profundamente judeo-cristiana. Dentro de una concepción claramente expresada en el Antiguo Testamento (incluso en sus libros apócrifos), donde la locura es una forma del pecado como oposición a la sabiduría divina, Jesucristo, que dice en el Sermón de la Montaña: "No penséis que he venido a abrogar la Ley o los Profetas; no he venido a abrogarla sino a consumarla", amenaza acto seguido con el fuego infernal al que ose llamar "loco" a su hermano ${ }^{10}$. Es sobre todo dentro de esta línea de pensamiento como cabe interpretar la interdicción del Ritual, que no considera lícito administrar la Sagrada Comunión a los locos, así como la reconciliación que sigue en Berceo a las curaciones hechas por los santos: "Una mugier que era natural de Palencia, / cayó por sus pecados en fiera pestilencia'" (SDom, 557ab); llevada ante el sepulcro del santo, recobra su voz para unirse a la respuesta litúrgica colectiva que acoge el anuncio de la lectura del Evangelio en la misa (SDom, 567):

La lection acabada, que es de sapiencia, el Preste a siniestro fizo su diferencia:

luego que ovo dicho el leedor "Sequencia[...]"

"Gloria tibi Domine", dixo la de Palencia.

y del vocabulario con que se lo expresa, véase mi artículo, "Los ojos de Berceo", Realidad, Buenos Aires, 5 (1949), 164-177.

${ }^{9}$ En la obra del poeta son notables algunos alardes léxicos. En el Sacrif, se trata de la fracción de la hostia en tres "zaticos" - la voz, de origen vasco, no siempre la vincula Berceo con el proverbio conocido del "romero fito"-: el uno de ellos es llamado "pedazo", y "el terceo cantiello" (275d, 276a y 277c). El "aventadero" de Nuestra Señora en San Miguel de la Tumba "en el seglar lenguage dicenli moscadero", sin perjuicio de que seis coplas más abajo se lo denomine sin más "flabello" (Milag, 321ab y 327c). Más opulento es el despliegue alrededor de la vasija a la que el burgués de Constantinopla confía la devolución de su deuda, llamada "sacco" (id., 666a), "bassel" (672c), "estui”" (674d), "tablero" (677b), "vaso" (678b: quizás "cellero" metafóricamente, 681b), "cesto" (694c) y "escrinno" (695c).

10 El artículo de James A. KeLso "Fool, folly", en J. Hastings (ed.) Encyclopaedia of Religion and Ethics (T. \& T. Clark, Edinburgh, 1964, t. 6), da razón de lo arriba afirmado y suministra la voz griega empleada en el capítulo 5 del Evangelio según San Mateo ( ), cuyos versículos 17 y 22 se citan por la traducción de Nácar-Colunga. 
Terminada la acción del pecado, apurada su locura, la grey recobra la oveja perdida.

Señalemos, para terminar, dentro de este cuadro perfectamente regulado, una ausencia, no por previsible menos significativa: la del loco fingido, sea por pasajera conveniencia (tema no desusado en las letras medievales: Tristán, Pathelin), sea de manera profesional (locos y bufones palaciegos), como tipo inusitado que es dentro de esta literatura edificante.

Daniel Devoto

C.N.R.S., Paris 